\title{
Correction to: Beyond Performance: Racial Prejudice and Whites' Mistrust of Government
}

\author{
Alexandra Filindra ${ }^{1}\left[\right.$ - Noah J. Kaplan ${ }^{1} \cdot$ Beyza E. Buyuker ${ }^{2}[0$ \\ Published online: 18 February 2022 \\ ○) Springer Science+Business Media, LLC, part of Springer Nature 2022
}

\section{Correction to: Political Behavior https://doi.org/10.1007/s11109-022-09774-6}

In this article the affiliation details of co-author Dr. Beyza E. Buyuker were incorrectly given as 'Indiana University, Chicago, USA' but should have been 'Indiana University, Bloomington USA.'

The original article has been corrected.

Publisher's Note Springer Nature remains neutral with regard to jurisdictional claims in published maps and institutional affiliations.

The original article can be found online at https://doi.org/10.1007/s11109-022-09774-6.

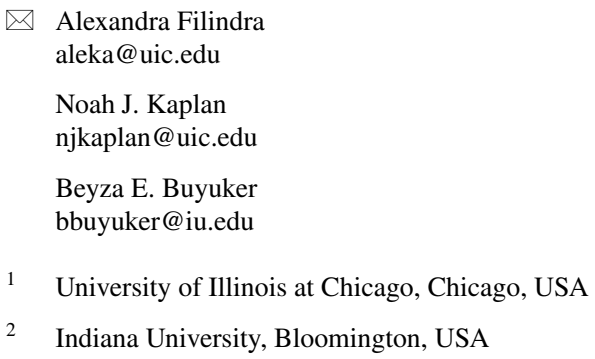

